\title{
On Teaching Analytical Chemistry
}

DOI: $10.1134 / \mathrm{S} 1061934811030191$

Zhurnal Analiticheskoi Khimii does not very often advert to problems in teaching, and this is wrong, because in Russia, problems in teaching analytical chemistry can only be regularly discussed within a few platforms.

In many Russian institutions of higher learning, courses in analytical chemistry are being modernized, in particular, specialized ones, aimed at teaching professional analysts. General courses are more conservative, but these are also updated; moreover, new textbooks and study guides, including those translated into Russian, the arrival of young teachers, and especially, numerous scientific conferences with teacher participation favor this process. Nevertheless, the informative part of general courses is more often traditional; a lot of time is devoted to chemical equilibria and classical methods of analysis. While they help to train an expert in chemistry, the detailed study of these sections takes time from the general problems of analytical chemistry, instrumental methods, and, at least, a brief account of the specific features of analysis of the most important objects. Up to now, in a number of higher schools, insufficient attention has been given to the analysis of organic and biological objects, ensuring quality of analysis, history of analytical chemistry, and trends in the development of chemical analysis.

In technological, engineering, and other postsecondary schools, the course in analytical chemistry is still rather absurdly divided into analytical chemistry itself and physicochemical methods of analysis, as though the latter are not a constituent of analytical chemistry (at classical universities, this division was eliminated long ago). Today very few specialized postsecondary schools, mainly engineering, graduate the analysts-engineers highly required in Russia.

Of course, the teaching methodology is being improved, in particular, using up-to-date technical facilities, but we can follow this direction more resolutely. We must develop, for example, curricula for virtual training on complex instruments and permit students train on such simulators. Perhaps it is also necessary to invent novel lecture experiments, to introduce research aspects into education, and to organize excursions to good scientific and industrial analytical laboratories.

Analytical divisions should adjust to modifications caused by the top-down reforms of the higher education system, first of all, to the two-stage educational model. Setting aside an evaluation of the expedience of these reforms (in my opinion, they were ill-conceived and rash), we must do our best to preserve all the good that has been accomplished earlier, to not lose the experience. We need textbooks for different educational stages. The system of regular retraining of teachers at special courses must be renewed. If we cannot introduce a sabbatical year, like in the United States, training for at least two or three months is highly necessary. We should also learn better how analytical chemistry is taught in other countries.

In progressive institutions of higher education, analytical chemistry divisions successfully cooperate with other divisions, as well as in educational tasks, thus harmonizing the sequence and depth of the study of separate subjects, sharing instruments, etc. Unfortunately, the heads of some schools sometimes merge analytical chemistry divisions with others. In establishing the large Siberian Federal University, the division of analytical chemistry existing at Krasnoyarsk University against all logic became the division of physical and analytical chemistry. At some universities, the divisions are renamed at their own initiative or, at least, by their consent. To increase their importance and strengthen their prestige, divisions of analytical chemistry have been renamed to include currently popular applied titles (certification, ecology, etc.). We can expect the introduction of, for example, nanotechnology, biogeotechnology, or some other field. However, interest in currently popular directions will peak and disappear, whereas analytical chemistry will remain.

The United Nations has declared year 2011 the International Year of Chemistry. We should use this opportunity to draw attention to analytical chemistry, as well as teaching it. 